\title{
The D152H mutation found in growth hormone insensitivity syndrome impairs expression and function of human growth hormone receptor but is silent in
} rat receptor

\author{
N Esposito ${ }^{1}$, J Wojcik ${ }^{1,2}$, J Chomilier ${ }^{2}$, J-F Martini ${ }^{1}$, P A Kelly ${ }^{1}$, \\ J Finidori ${ }^{1}$ and M-C Postel-Vinay ${ }^{1}$ \\ ${ }^{1}$ Unité 344, Endocrinologie Moléculaire, Institut National de la Santé et de la Recherche Médicale, \\ Faculté de Médecine Necker Enfants Malades and ${ }^{2}$ Laboratoire de Minéralogie-Cristallographie, \\ Universités Paris VI et Paris VII, CNRS URA09 Paris, France \\ (Requests for offprints should be addressed to M-C Postel-Vinay, INSERM Unité 344, Faculté de \\ Médecine Necker Enfants Malades, 156 rue de Vaugirard, 75730 Paris Cedex 15, France)
}

\begin{abstract}
In two patients with growth hormone $(\mathrm{GH})$ insensitivity syndrome (Laron syndrome), in whom the $\mathrm{GH}$ receptor is able to bind the hormone, the $\mathrm{D} 152 \mathrm{H}$ mutation was identified, and lack of dimerization was proposed to explain $\mathrm{GH}$ resistance in these patients. To examine further the consequences of the substitution of conserved aspartate 152 on the function of the GH receptor (GHR), we reproduced the mutation in vitro on the full length $\mathrm{GH}$ receptor cDNA from man and rat. Effects of the mutation on expression and activity of the GHR were analyzed in 293 cells transfected with wild-type and mutant GHR cDNAs. Mutant human receptor protein was expressed at a lower level than wild-type receptor and its activity was reduced: GH-dependent signal transducer and activator of transcription 5 (Stat5)-mediated transactivation of a reporter gene was lower in 293 cells transfected with mutant GHR cDNA than in transfected cells expressing a comparable level of wild-type GHR. The membrane-bound form of the mutant and of the wild-type human GHR were able
\end{abstract}

to homodimerize, as suggested by the size of the complexes detected in cross-linking experiments with ${ }^{125} \mathrm{I}$-human (h) $\mathrm{GH}$, and also by the activity in the functional test. With the soluble GHR resulting from proteolysis of the wild-type membrane form, no dimeric complexes could be detected. However, when a soluble receptor lacking the transmembrane and cytoplasmic domains of the receptor was expressed, wild-type and not mutant GH binding protein (GHBP) was able to form dimers in the presence of hGH. The amino acid substitution has no effect on either expression or function of the rat receptor. Structural modeling of D152H soluble human and rat GHR (GHBP) supports the species-specific functional consequences of the mutation. Evaluation of the functional importance of the mutation strongly suggests that impairment in expression and activity of the mutant receptor, rather than complete lack of dimerization, explains the GH resistance of the patients.

Fournal of Molecular Endocrinology (1998) 21, 61-72

\section{INTRODUCTION}

The growth hormone (GH) receptor (GHR) belongs to the superfamily of cytokine receptors (Bazan 1990). In addition to the membrane-bound receptor, a GH binding protein (GHBP) has been characterized in the serum of man (Baumann et al. 1986) and of many other species, including rabbit (Ymer \& Herington 1985), rat (Baumbach et al.
1989), and mouse (Peeters \& Friesen 1977). The amino acid sequence of the GHBP is identical to that of the extracellular domain of the membranebound GH receptor (Leung et al. 1987). In rat and mouse, GHR and GHBP are encoded by two distinct $m R N A s$ generated by alternative splicing of a single primary transcript (Baumbach et al. 1989, Smith et al. 1989). In tissues of other mammals, including man, only one mRNA has been identified 
by Northern blot analyses (Delehaye-Zervas et al. 1994) and it has been suggested that, in these species, GHBP is mainly produced by proteolysis of the membrane GHR (Spencer et al. 1988, Sotiropoulos et al. 1993).

Structural, mutational, and functional studies have provided evidence that ligand-induced dimerization of receptors of this family is a crucial step in receptor activation leading to signal transduction (Heldin 1995). High resolution mutational analysis of the human GHR and X-ray crystallographic studies have shown that the GH-GHR complex is a homodimer consisting of one molecule of hormone interacting with two receptors (Cunningham et al. 1991, De Vos et al. 1991, Fuh et al. 1992).

Laron syndrome is a rare genetic disease with complete GH resistance due to molecular defects in the GHR gene (Laron et al. 1966, Berg et al. 1993). In most cases, GH binding activity of binding protein $(\mathrm{BP}) /$ receptor is undetectable and this is consistent with a defect in the extracellular domain of the GHR, which results in impaired hormone binding (Daughaday \& Trivedi 1987). However, recent reports have described patients with positive GHBP (Buchanan et al. 1991, Savage et al. 1993). In two such patients, the substitution of aspartate by histidine at position 152 in the extracellular domain of the GHR was demonstrated (Duquesnoy et al. 1994). This group reproduced the mutation in human GHR cDNA which was transiently transfected in COS cells, and they also engineered a soluble GHR protein. While they reported normal binding characteristics for the membranebound mutant receptor, their results, based on chromatographic analyses, suggested that the recombinant soluble mutant receptor was unable to dimerize.

Our goal was to characterize better the functional consequences induced by substitution of the conserved aspartate residue by histidine at position 152 (D152H), and to do the study using human (h) and rat (r) GHRs. We compared the expression of both the membrane-bound form and the soluble receptor in cells transfected with wild-type or mutant GHR cDNAs. A functional test to measure activity of the receptor forms using the activation of signal transducer and activator of transcription 5 (Stat5) by GHR has been reported (Wood et al. 1995). Wild-type or the mutant GHR cDNA, and a reporter gene containing DNA binding element for Stat5 were used to cotransfect 293 cells. Our results show that the amino acid substitution in human GHR results in partial defects of expression, dimerization, and function of the receptor, the combination of which could explain the GH resistance in the patients. In addition, although the aspartate residue is conserved among species, the functional consequences of its substitution vary, since expression and activity of $\mathrm{D} 152 \mathrm{H}$ rat GHR are not altered.

Moreover, three dimensional models have been constructed for wild-type and mutant forms of human and rat receptors. To understand further the effects of point mutations, trajectories of molecular dynamics have been computed and compared between mutant and wild-type forms of the receptors.

\section{MATERIALS AND METHODS}

\section{Construction of expression plasmids and mutagenesis}

The full length hGHR cDNA coding sequence was obtained from W Wood (Genentech) (Leung et al. 1987). The cDNA was subcloned into BamHISnaBI sites of pcDNA1-derived mammalian expression vector that contains a cytomegalovirus promoter, and the bacteriophage $\mathrm{f} 1$ intergenic region. Rat GHR cDNA (a gift from G Norstedt) was subcloned into pcDNA3 vector. Singlestranded DNA from pcDNA1 and pcDNA3 was isolated. Oligonucleotides containing the $\mathrm{G} \rightarrow \mathrm{C}$ transversion, resulting in the substitution of aspartate in histidine at amino acid 152, were used to mutagenize the receptor cDNA. The resulting mutation was confirmed by DNA sequencing.

Site-directed mutagenesis was performed to produce soluble wild-type hGHR (wt sGHBP) and soluble D152H hGHR (D152H sGHBP) encoding the corresponding soluble secreted forms of the receptor using oligonucleotide 5-CTTCTTCAC ATGTTTATTGGCTCATC-3 which introduced a translation stop codon at the amino acid 239 of the hGHR cDNA sequence.

\section{Cell culture and transfection}

Dulbecco's modified Eagle's medium (DMEM nut F12) containing $10 \%$ fetal calf serum (FCS), glutamine, and antibiotics ('growth medium') was used to grow 293 cells to confluence at $37^{\circ} \mathrm{C}$ in a humidified atmosphere of $5 \% \mathrm{CO}_{2}$. Three hours prior to transfection, the cells were plated in 'rich medium' (2/3 DMEM nut F12, 1/3 DMEM with $4.5 \mathrm{~g} / \mathrm{l}$ glucose, $10 \% \mathrm{FCS}$, glutamine, and antibiotics) in six-well plates. Transfections were performed using the calcium phosphate method: the DNA solution (plasmid, $0.25 \mathrm{M} \mathrm{CaCl}_{2}$ ) was mixed with BES (N,N-bis [2-hydroxyethyl]-2aminoethanesulfonic acid)-buffered saline $(50 \mathrm{mM}$ BES, $\left.280 \mathrm{mM} \mathrm{NaCl}, 1.5 \mathrm{mM} \mathrm{Na} \mathrm{HPO}_{4}\right)$, pH 6.9 . 
The mix was added to each well and then the cells were incubated for $15-20 \mathrm{~h}$ at $37{ }^{\circ} \mathrm{C}$ in $3 \% \mathrm{CO}_{2}$, and replaced in $5 \% \mathrm{CO}_{2} 24 \mathrm{~h}$ prior to assay.

\section{Binding assays}

${ }^{125} \mathrm{I}$-hGH was prepared using Chloramine-T; its specific activity ranged from 80 to $120 \mu \mathrm{Ci} / \mu \mathrm{g}$. Twenty-four hours after transfection, the cells were serum-starved for $12 \mathrm{~h}$. The culture medium was removed and concentrated (20-fold) to be analyzed for the presence of GHBP. Cells were washed with PBS containing 1\% BSA and incubated with ${ }^{125} \mathrm{I}-\mathrm{hGH} \quad\left(10^{5}\right.$ c.p.m./well $)$ for $3 \mathrm{~h}$ at room temperature, in the absence or presence of various concentrations of unlabeled hGH. The cells were then washed with the same buffer and solubilized in $1 \mathrm{ml} \mathrm{NaOH}(1 \mathrm{M})$ for counting.

GHBP was assayed in culture media using HPLC gel filtration (Tar et al. 1990). Twentyfold concentrated supernatants containing either the wild-type or the D152H mutant soluble GHR were incubated with ${ }^{125}$ I-labeled hGH $\left(1.5 \times 10^{5}\right.$ c.p.m. $)$

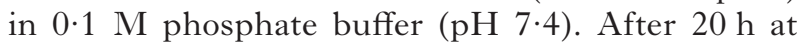
$4{ }^{\circ} \mathrm{C}$, the reaction products were analyzed by gel filtration on an HPLC Protein Pak 300 SW column (Waters, Milford, MA, USA). Elution was performed with degassed buffer $\left(0 \cdot 1 \mathrm{M} \mathrm{Na}_{2} \mathrm{SO}_{4}, 0 \cdot 1 \mathrm{M}\right.$ $\mathrm{K}_{2} \mathrm{HPO}_{4}$, pH 7.0) pumped at a rate of $0.5 \mathrm{ml} / \mathrm{min}$. Radioactivity was recorded on line using a Berthold LB2040 detector (Berthold, Elancourt, France) connected to a Compaq computer. Scatchard analyses were performed with the program Ligand (Munson \& Rodbard 1980).

Membrane fractions of cells transfected with $5 \mu \mathrm{g}$ plasmid were prepared by differential centrifugation. Membrane protein $(300 \mu \mathrm{g})$ was incubated with ${ }^{125} \mathrm{I}-\mathrm{hGH}\left(1.5 \times 10^{5}\right.$ c.p.m. $)$ as described in Dinerstein et al. (1995). Bound and free hormones were separated by centrifugation at $17000 \boldsymbol{g}$ for $15 \mathrm{~min}$, and the radioactivity in the pellet was counted.

\section{Cross-linking studies}

Cells were grown in six-well plates and transfected with $5 \mu \mathrm{g}$ plasmid containing the wild-type or the mutant cDNA. ${ }^{125}$ I-hGH $\left(5 \times 10^{5}\right.$ c.p.m./well $)$ was added to the dishes in the absence or presence of $5 \mu \mathrm{g} / \mathrm{ml}$ unlabeled $\mathrm{hGH}$, and incubated for $30 \mathrm{~min}$ at $37^{\circ} \mathrm{C}$. Cells were then washed with PBS, and $2 \mathrm{ml}$ PBS were added to each well. Disuccinimidylsuberate $(0.5 \mathrm{mM})$ was added to the cells and incubated for $20 \mathrm{~min}$ at room temperature. The reaction was stopped with $2 \mathrm{ml}$ $50 \mathrm{mM}$ Tris, $150 \mathrm{mM} \mathrm{NaCl}$. Electrophoresis was performed on an $8 \%$ SDS polyacrylamide gel. The gel was dried and exposed to X-ray film (Kodak, France).

\section{Transcription assays}

We prepared the fusion gene consisting of lactogenic hormone response element (LHRE) linked to the luciferase reporter gene. It was constructed using a pUC18 vector containing the thymidine kinase (TK) minimal promoter linked to luciferase reporter gene (TK-luc) subcloned into the BamHI site. Double stranded oligonucleotides, 5-CTG CAGTGTGGACTTCTTGGAATTAAGGGAC TTTTGCTGCAG-3 for LHRE (six copies) were inserted into the PstI site of the vector. 293 cells were plated in 6 -well plates at $0.4 \times 10^{6}$ cells per well before being transfected with 0.001 to $0 \cdot 1 \mu \mathrm{g}$ expression vector containing the different mutant forms of GHR, $1.5 \mu \mathrm{g}$ LHRE/TK-luciferase reporter gene and $3 \mu \mathrm{g}$ pCH110 ( $\beta$-galactosidase expression vector; Pharmacia, Bromma, Sweden). Cells were incubated for $24 \mathrm{~h}$ with serum-free medium containing $20 \mathrm{nM} \mathrm{hGH}$ and $250 \mathrm{mM}$ dexamethasone or $250 \mathrm{mM}$ dexamethasone alone. Cells were lyzed as described previously (Dinerstein et al. 1995) and whole cell extracts were used for determination of luciferase and $\beta$-galactosidase activities. Luciferase activity was normalized to $\beta$-galactosidase activity. Fold induction of luciferase activity (in the presence of hormone) was calculated from the basal level (in the absence of hormone).

\section{Molecular modeling}

Four GH-(GHBP $)_{2}$ molecular models were built in order to study structural effects of the D152H mutation in human and rat receptors. The common pattern used for molecular modeling was the human wild-type complex hGH-(hGHBP) $)_{2}$ as described by De Vos et al. in 1991 and revised in the Protein Data Bank (Bernstein et al. 1977) in 1994 (PDB:3HHR). The human D152H mutant complex, in which each receptor bears the D152H mutation, was constructed using InsightII (Biosym, San Diego, CA, USA) to perform point mutations. As extracellular sequences of hGHR and rGHR are $70 \%$ identical, the ExPASy (Peitsch 1995) automatic modeling server was used to build a hGH$(\mathrm{rGHBP})_{2}$ complex based on the human complex. Then a D152H mutant rat complex was built. All these complexes were protonated and energy minimized (1000 steps) in vacuo using the CHARMM (Brooks et al. 1996) force field (X-Plor program, Brünger et al. 1989). 
Extracellular C-terminal domains of receptors were solvated in a box containing 2200 water molecules at $300 \mathrm{~K}$, corresponding to two layers. As the hormone binding activity of these receptors is normal, the hormone and the $\mathrm{N}$-terminal domains are kept as a referential: these regions were not solvated and were constrained (fixed coordinates) during the molecular dynamics. Then structures were energy minimized (2000 steps) using the CHARMM force field and first 100 ps, then 400 ps molecular dynamics were performed. A temperature of $300 \mathrm{~K}$ is stable after 20 ps. Final solvated complexes were once again energy minimized (500 steps).

Surface accessibility (S) calculations were performed using the Access program (Richmond \& Richards 1978). Interface surface between two A and $\mathrm{B}$ proteins was calculated by computing the difference between the sum of the accessibility surface of each protein and the accessibility surface of the complex: $\mathrm{S}($ interface $)=\mathrm{S}(\mathrm{A})+\mathrm{S}(\mathrm{B})-\mathrm{S}(\mathrm{A}+\mathrm{B})$.

The axes of the extracellular $\mathrm{C}$-terminal domains of GHR have been approximated by defining 'slices' and calculating the center of gravity for each slice. Choice of these slices was determined according to the general orientation of domains in the human GH- (GHBP $)_{2}$ complex. Four slices were defined for each domain, and for each one, a peripheric atom was chosen to detect rotations: it corresponds to $\alpha$ carbons of residues 145, 161, 191 and 199 .

\section{RESULTS}

\section{Expression of GH receptors in 293 cells}

Expression of the wild-type (wt) GH receptors (wt GHRs) and of the mutant D152H GHRs was first examined by measuring hGH binding in transiently transfected 293 cells. Receptor expression as a function of the quantity of cDNA transfected in 293 cells is shown in Fig. 1. At all amounts of plasmid transfected, specific binding of ${ }^{125} \mathrm{I}-\mathrm{hGH}$ to cells expressing mutant human GHR (hGHR) was much lower than binding to cells expressing wt hGHR, the defect being less severe when more than $1 \mu \mathrm{g}$ plasmid was used in transfections. Scatchard analyses from competition experiments were carried out with cells transfected with $5 \mu \mathrm{g}$ plasmid encoding the hGHR: the number of sites per cell transfected with the vector coding for wt hGHR was twofold higher than in cells transfected with the vector coding for the mutant hGHR. The dissociation constant $\left(K_{\mathrm{d}}\right)$ ranged from 0.92 to $1.90 \mathrm{nM}$, with a small $1 \cdot 7$-fold difference in affinity between the wt hGHR and D152H hGHR (Table 1).

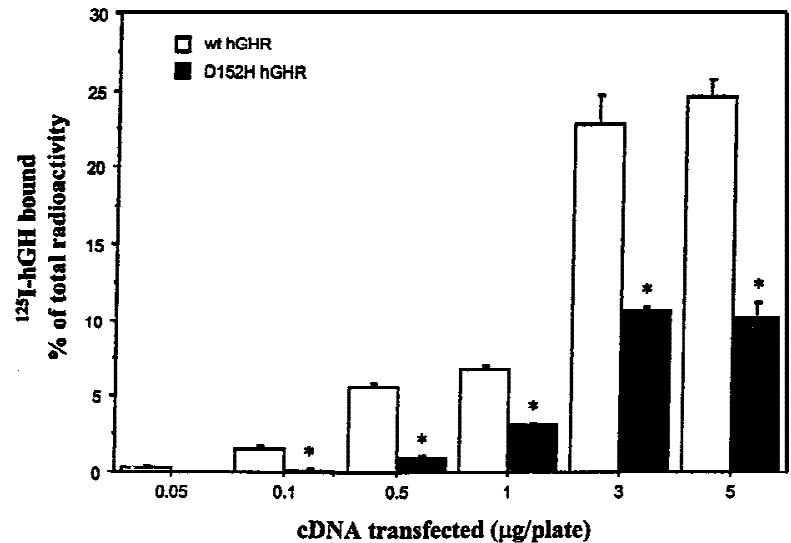

FIGURE 1. Specific binding of ${ }^{125} \mathrm{I}-\mathrm{hGH}$ to wt and D152H hGHRs as a function of increasing amount of cDNA transfected. Transiently transfected 293 cells were incubated with ${ }^{125} \mathrm{I}-\mathrm{hGH}\left(10^{5}\right.$ c.p.m. $)$ in the absence or presence of unlabeled hGH $(2 \mu \mathrm{g})$. The specific binding is expressed as the percentage of total radioactivity. Each value represents the mean \pm s.E.M. of triplicate measurements from one of three independent experiments. No specific hGH binding was detected in cells transfected with $0.05 \mu \mathrm{g}$ plasmid of D152H hGHR cDNA. ${ }^{*} P<0 \cdot 05$ compared with wt hGHR.

Comparable results were obtained in ten independent experiments and with different plasmid preparations. Specific binding of ${ }^{125} \mathrm{I}-\mathrm{hGH}$ to membranes of transiently transfected (with $5 \mu \mathrm{g}$ plasmid) 293 cells confirmed the lower binding in membranes of cells expressing the mutant human receptor and suggested absence of abnormal receptor cellular trafficking for the mutant receptor (not shown).

There was no significant difference in $\mathrm{GH}$ binding affinity in 293 cells transfected with plasmid encoding wt or mutant rat GHR (Table 1). The number of binding sites was lower in cells expressing the D152H rat GHR.

\section{Soluble forms of GHR in the culture medium of transfected 293 cells}

GHBPs of non murine species are thought to be produced by proteolysis of the membrane-bound GH receptor. We analyzed culture media from 293 cells transfected with full length cDNA encoding either wt (thick line) or D152H mutant form of hGHR (thin line) (Fig. 2A). Soluble GH receptors, generated by proteolysis were produced in the two culture media and superimposable elution profiles were observed. Two peaks were detected, the second representing free ${ }^{125} \mathrm{I}-\mathrm{hGH}$ (Fig. 2A). The 
TABle 1. Characteristics of hGH binding to 293 cells transfected with different forms of the GH receptor. 293 cells were transfected with $5 \mu \mathrm{g}$ cDNA of the different receptor forms. Binding affinities $\left(K_{\mathrm{d}}\right)$ and number of sites per cell have been calculated from Scatchard plots obtained from competition experiments. Mean \pm S.E.M. of the results obtained in three experiments are presented

wt hGHR

D152H hGHR

wt ratGHR

D152H rat GHR

\begin{tabular}{|c|c|}
\hline $\boldsymbol{K}_{\mathbf{d}}(\mathrm{nM})$ & Sites/cell \\
\hline $1 \cdot 01 \pm 0 \cdot 09$ & $333500 \pm 39500$ \\
\hline $1 \cdot 70 \pm 0 \cdot 20$ & $186000 \pm 9000$ \\
\hline $1 \cdot 29 \pm 0 \cdot 15$ & $363000 \pm 5000$ \\
\hline $1 \cdot 11 \pm 0 \cdot 05$ & $277500 \pm 24500$ \\
\hline
\end{tabular}

elution times of the peak corresponding to wt GHBP and to mutant GHBP are very close: $17 \mathrm{~min}$ $12 \mathrm{~s}$ and $17 \mathrm{~min} 16 \mathrm{~s}$ respectively. We never observed high molecular weight radioactive peaks representing potential receptor dimers in elution profiles obtained with media containing wt or mutant GHBP whatever the amount of concentrated media used in the experiments (data not shown). Binding characteristics of wt and mutant GHBP were also analyzed by Scatchard plots obtained from competition experiments. Comparable dissociation constants $(4.5 \mathrm{nM}$ for the wt GHBP and 5.0 nM for the mutant soluble receptor), similar to values reported for human plasma GHBP (Tar et al. 1990) were found. However, the maximum binding capacity was twofold lower for the mutant GHBP $(2 \cdot 6 \mathrm{nM})$ compared with the wt GHBP $(5 \cdot 5 \mathrm{nM})$. No $\mathrm{GH}$ binding activity was detected in the media of untransfected 293 cells.

Different results were obtained when media containing an artificially secreted soluble GHBP were studied. A stop codon was introduced at position 239 to generate a GHR protein with no transmembrane domain, as previously performed by Duquesnoy et al. (1994). Elution profiles are shown in Fig. 2B: under such conditions, a difference in the elution times of the complexes of ${ }^{125} \mathrm{I}-\mathrm{hGH}$ with the wt and the mutant extracellular domain of GHR is observed. With medium containing the extracellular domain of GHR, the radioactive complex is shifted towards a higher molecular weight, suggesting the presence of receptor dimers (Fig. 2C); there is a difference of $60 \mathrm{~s}$ between the elution times of the peaks corresponding to the highest $(50 \mu \mathrm{l})$ and the lowest $(0 \cdot 5 \mu \mathrm{l})$ volume of medium. Elution times obtained with various amounts of media containing the secreted mutant GHBP remain identical whatever the concentration of GHBP used; it corresponds to the elution time expected for a complex consisting of one receptor molecule and one hormone molecule (not shown). Thus, under these particular experimental conditions, the soluble, secreted mutant GHBP lacks the ability to dimerize.

\section{Cross-linking studies}

Cells were transiently transfected with wt or mutant forms of human or rat GHR, and cross-linking of ${ }^{125} \mathrm{I}-\mathrm{hGH}$ to the different GHR forms was performed. The complexes were analyzed by SDS/PAGE and detected by autoradiography (Fig. 3 ). Two complexes, of approximately 280 and $150 \mathrm{kDa}$, were revealed for wt and D152H GHR; both are specific since their formation was blocked by an excess of unlabeled hGH. The size of the two complexes suggests that the $150 \mathrm{kDa}$ form represents one hormone molecule bound to one receptor, while the $280 \mathrm{kDa}$ complex could consist of a receptor dimer and one hGH molecule. As a control, cells were also transfected with a cDNA encoding a truncated form of human GHR $\left(\mathrm{GHR}_{1-317}\right)$ missing 303 residues in the carboxyterminal region of the cytoplasmic domain; the two complexes obtained were of smaller size compared with those formed with the full length receptor (Fig. 3). The cross-linking studies suggest that both wild-type and mutant GHRs are able to dimerize.

\section{Functional studies of GHR forms}

The activation of the reporter gene in cells transfected with wt or D152H GHR cDNA from human (A) and rat (B) is shown in Fig. 4. hGH stimulation of luciferase activity was measured in cells transfected with various quantities of GHR cDNAs. In cells transfected with human GHR cDNAs (wt or mutant), the relative luciferase units measured in stimulated cells and the fold induction increased with the amount of cDNA transfected. In cells transfected with the mutant GHR, the GH effect, as also expressed by the fold induction, was much lower than in cells transfected with wt hGHR cDNA (Fig. 4A).

In contrast to that which we observed for human GHR, the mutation D152H did not alter the activity of rat GHR in the functional test. However, it can be observed in Fig. 4B that the fold induction obtained at $0 \cdot 1 \mu \mathrm{g}$ cDNA transfected for both the wt and the mutant rat GHR is lower than the fold induction reached at $0.01 \mu \mathrm{g} \mathrm{cDNA}$, and that it is due to an increased basal level of luciferase activity; the high basal level could be related, at least in part, to high receptor expression.

The dose-response of hGH on Stat5 transcriptional activity in 293 cells expressing wt or D152H hGHR is shown in Fig. 5. Cells were transfected 
with $0 \cdot 1 \mu \mathrm{g}$ plasmid of either wt or D152H hGHR or with $1 \mu \mathrm{g}$ plasmid of D152H hGHR to avoid a low expression of mutant receptors; under these conditions, the specific binding of ${ }^{125} \mathrm{I}-\mathrm{hGH}$ to the transfected cells was $1 \cdot 6 \%, 0 \cdot 1 \%$, and $3 \cdot 3 \%$ of the radioactivity respectively. $\mathrm{GH}$ stimulation of luciferase activity was measured in the three cell cultures. A GH effect was detected with $10 \mathrm{ng} / \mathrm{ml}$ $\mathrm{GH}$ and reached a maximum at $1 \mu \mathrm{g} / \mathrm{ml}$ (Fig. 5). At higher hormone concentrations, transcriptional activity decreased. A bell-shaped curve was observed under the three transfection conditions, suggesting that dimerization of $\mathrm{GH}$ receptors also
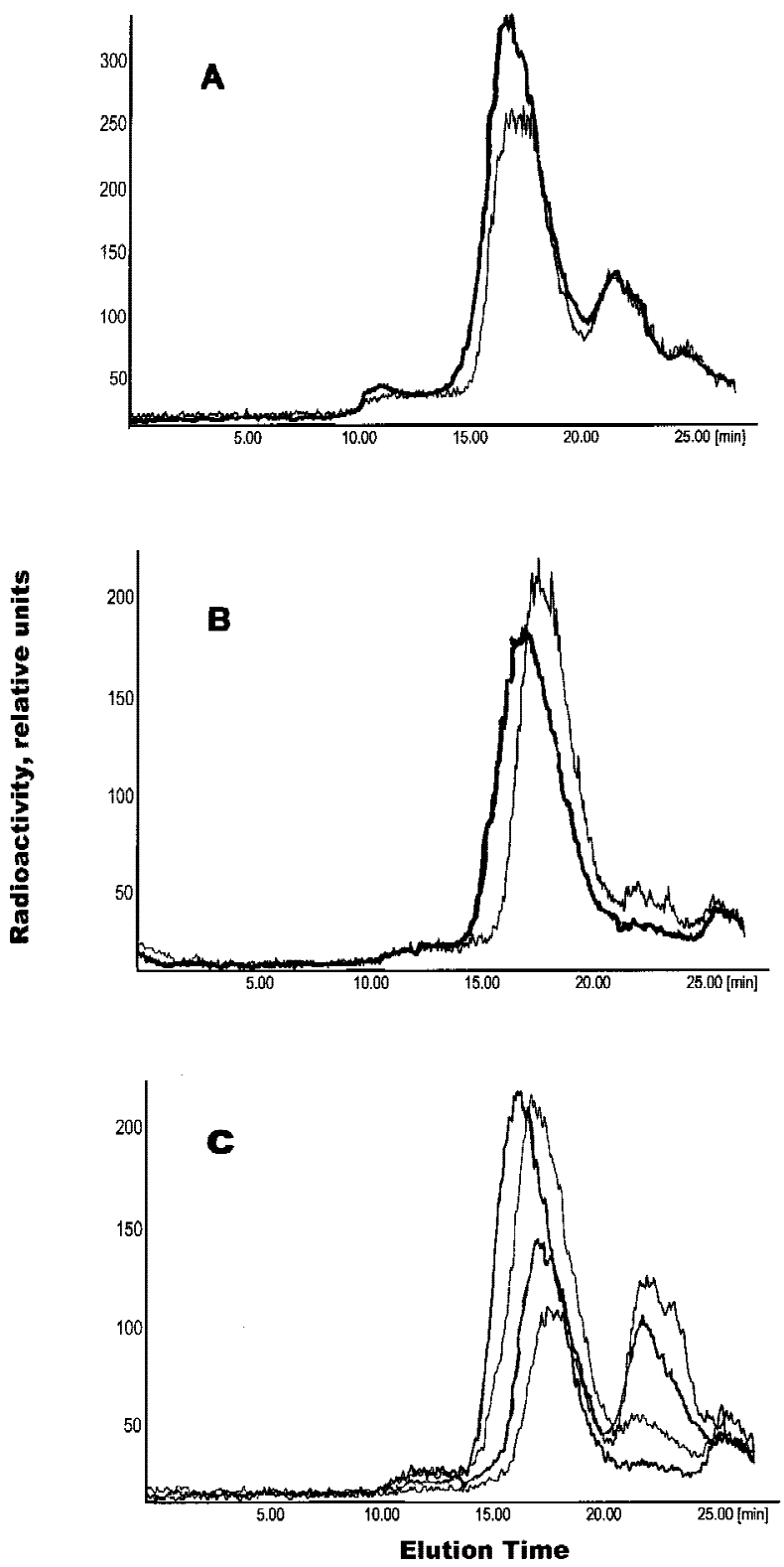

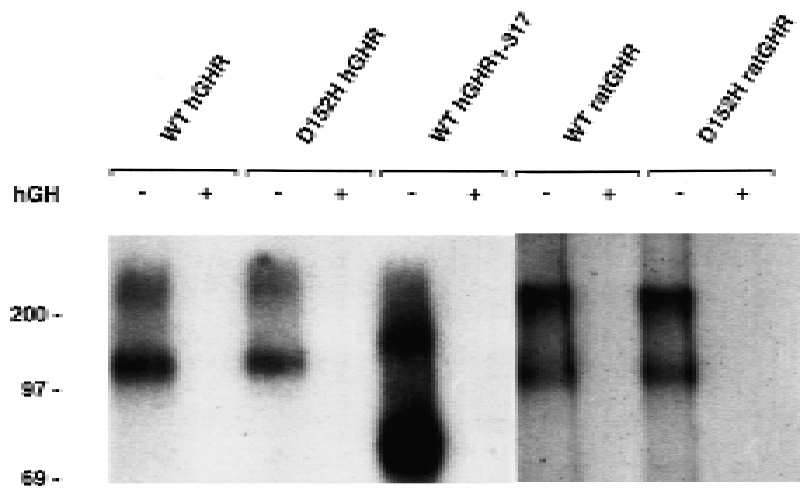

FIGURE 3. Autoradiography of cross-linked ${ }^{125} \mathrm{I}-\mathrm{hGH}$ to GH receptor forms. 293 cells expressing wt or D152H human or rat GHR, and human $\mathrm{GHR}_{1-317}$ as a control were incubated with ${ }^{125} \mathrm{I}-\mathrm{hGH}\left(5 \times 10^{5}\right.$ c.p.m. $)$ without or with an excess of unlabeled hGH. Solubilized proteins were analyzed on an $8 \%$ SDS-polyacrylamide gel. Numbers on the left indicate molecular mass $(\mathrm{kDa})$ of protein markers.

occurs in cells expressing the mutant receptor. The median effective concentration of stimulation $\left(\mathrm{EC}_{50}\right)$ of $\sim 30 \mathrm{ng} / \mathrm{ml}$ was identical for cells expressing wt or D152H hGHR (Fig. 5). However, luciferase activity measured in cells expressing the mutant hGHR was always lower than in cells expressing the wt hGHR, even though the former cells were transfected with ten times more cDNA and had a twofold higher level of GH binding. For the same amount of GHR cDNA transfected $(0 \cdot 1 \mu \mathrm{g}$ plasmid/ plate), the D152H hGHR was eight times less active on gene transcription than the wt hGHR, as shown in Fig. 5.

FIGURE 2. Elution profiles of ${ }^{125} \mathrm{I}-\mathrm{hGH}$ incubated with concentrated culture medium of transfected 293 cells. The panels show the elution profiles from HPLC gel-filtration column of ${ }^{125} \mathrm{I}-\mathrm{hGH}$ incubated with concentrated supernatants of 293 cells expressing (A) the wt proteolyzed form of the GHR (wt GHBP) (thick line) or the D152H GHBP (thin line), and (B) the wt secreted form of the GHR (wt sGHBP) (thick line) or D152H sGHBP (thin line). The elution times of the complexes of wt GHBP, D152H GHBP, wt sGHBP, and D152H sGHBP are estimated at $17 \mathrm{~min} 16 \mathrm{~s}$, $17 \min 12 \mathrm{~s}, 16 \min 42 \mathrm{~s}$, and $17 \min 26 \mathrm{~s}$ respectively. (C) The same concentration of ${ }^{125}$ I-hGH $\left(\sim 10^{5}\right.$ c.p.m. $)$ was incubated with $50,5,1$, or $0 \cdot 5 \mu$ l medium expressing the wt sGHBP. The complexes elute at different times: the peak is seen at $16 \mathrm{~min} 15 \mathrm{~s}$ for $50 \mu \mathrm{l}$ medium, at $16 \mathrm{~min} 41 \mathrm{~s}$ for $5 \mu \mathrm{l}$ medium, at $16 \mathrm{~min} 51 \mathrm{~s}$ for $1 \mu \mathrm{l}$ medium, and at $17 \mathrm{~min} 15 \mathrm{~s}$ for $0.5 \mu \mathrm{l}$ medium. 

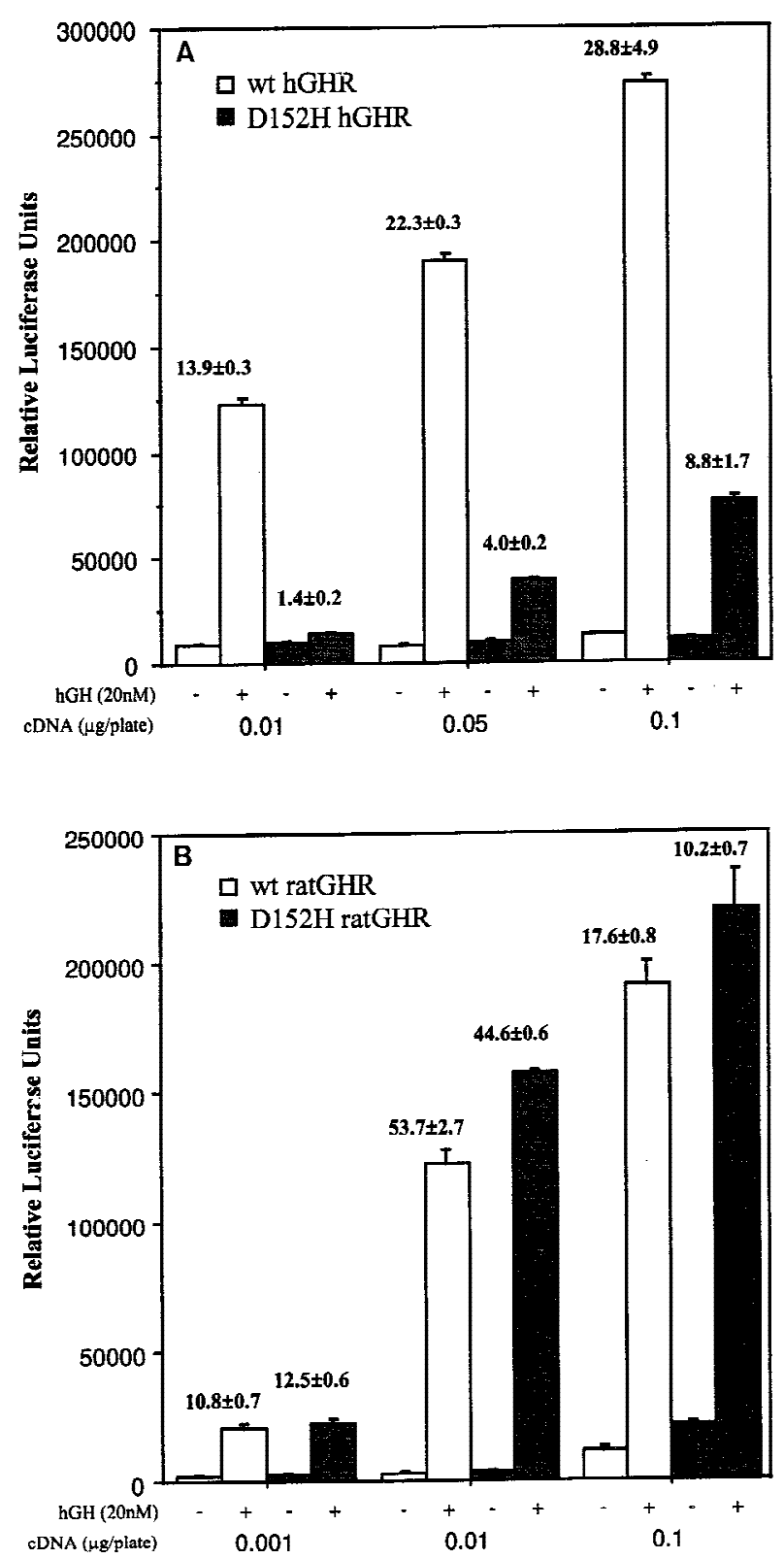

FIGURE 4. Transcriptional activity of GHR forms in the LHRE/TK-luciferase system. 293 cells were transiently co-transfected with various amounts of plasmids encoding either the wild-type or the indicated mutated GHR cDNA, together with the fusion gene LHRE/TK-luciferase. After transfection, cells were incubated in the presence $(+)$ or absence $(-)$ of $20 \mathrm{nM}$ $\mathrm{hGH}$ for $24 \mathrm{~h}$. Results are expressed in luciferase units, and also, above the bars, in fold induction of luciferase activity due to GH (see Materials and Methods). Results are shown for cells expressing different forms of human (A) and rat (B) receptors. Each value represents the mean \pm S.E.M. of triplicate measurements.

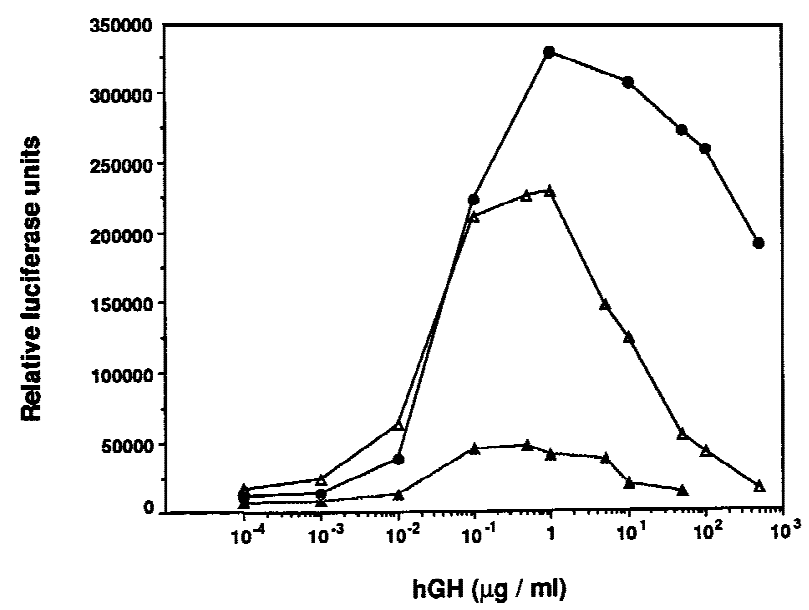

FIGURE 5. Transcriptional activity induced by hGH in 293 cells transfected with $0 \cdot 1 \mu \mathrm{g}$ plasmid/plate of wt hGHR $(\bigcirc)$, and $0 \cdot 1(\boldsymbol{\Delta})$ or $1(\triangle) \mu \mathrm{g}$ plasmid/plate of D152H hGHR cDNA. Cells were stimulated in serum-free medium with various concentrations of hGH for $12 \mathrm{~h}$ and luciferase units were measured. Values represent the mean of triplicate measurements. One representative experiment out of three is shown.

\section{Effects of the mutation on the GHR dimer structure}

Stuctural analysis based on distance and angular measurements shows five possible hydrogen bonds between the two human wt receptors (Table 2). The two Asp152 residues are involved in three of the five stabilizing interactions between receptors and seem to be crucial for dimerization. These potential hydrogen bonds differ from those found by De Vos et al. in 1991, presumably because we used the latest structure available in the Protein Data Bank (1994). Three possible hydrogen bonds were still found after molecular dynamics in the $\mathrm{D} 152 \mathrm{H}$ mutant human complex (Table 2). Distance and angular measurements suggest that the D152H mutation in hGHR does not break the dimerization (Fig. 6), although the interface surface is reduced from $480 \AA^{2}$ in the wt to $390 \AA^{2}$ in the mutant receptor.

In the case of the rat receptor, the interface stability does not seem to be affected by the D152H mutation, as can be observed from surface calculations (about $220 \AA^{2}$ for both wt and mutant rat complexes). However, the number of hydrogen bonds between receptors decreased from three in the wt to two in the mutant receptor (Table 2).

Schematic representation of the axes was used to visualize changes induced by the mutation on the relative orientation between $\mathrm{C}$-terminal domains of GHBP in human and rat complexes (Fig. 7). In the human complex, the two mutant GHBP C-terminal 
TABLE 2. Hydrogen bonds in intermolecular interface of $\mathrm{GH}$ receptor dimers. The possible intermolecular hydrogen bonds between two GHBP molecules and the distance between atoms of residues involved are presented

\begin{tabular}{|c|c|c|c|}
\hline & GHBP-I atom & GHBP-II atom & Distance $(\AA)$ \\
\hline \multirow[t]{5}{*}{ Human wildtype } & $\mathrm{O}_{\delta 1} \mathrm{ASP}-152$ & HH TYR-200 & $1 \cdot 98$ \\
\hline & $\mathrm{H}_{\varepsilon 2}$ HIS-150 & $\mathrm{O}_{\delta 1} \mathrm{ASN}-143$ & 1.99 \\
\hline & HN LEU-146 & $\mathrm{O}_{\gamma}$ SER-201 & $1 \cdot 95$ \\
\hline & $\mathrm{H}_{\gamma 1}$ THR-147 & $\mathrm{O}_{\delta 2} \mathrm{ASP}-152$ & $2 \cdot 00$ \\
\hline & $\mathrm{H}_{\gamma}$ SER-145 & $\mathrm{O}_{\delta 1}$ ASP-152 & $1 \cdot 96$ \\
\hline \multirow[t]{3}{*}{ Human D152H } & O ALA-151 & HH TYR-200 & $1 \cdot 90$ \\
\hline & $\mathrm{O}_{\gamma 1}$ THR-147 & $\mathrm{H}_{\varepsilon 2}$ HIS-152 & $1 \cdot 96$ \\
\hline & $\mathrm{H}_{\gamma}$ SER-145 & $\mathrm{O}_{\gamma}$ SER-201 & $1 \cdot 91$ \\
\hline \multirow[t]{3}{*}{ Rat wild type } & $\mathrm{H}_{\gamma}$ SER-201 & OH TYR-200 & 1.98 \\
\hline & HN LEU-146 & $\mathrm{O}_{\gamma}$ SER-201 & 1.98 \\
\hline & $\mathrm{H}_{\gamma}$ SER-145 & $\mathrm{O}_{\delta 2}$ ASP-152 & $2 \cdot 03$ \\
\hline \multirow[t]{2}{*}{ Rat D152H } & O TYR-200 & HH TYR-200 & $1 \cdot 86$ \\
\hline & HN LEU-146 & $\mathrm{O}_{\gamma}$ SER-201 & $1 \cdot 96$ \\
\hline
\end{tabular}
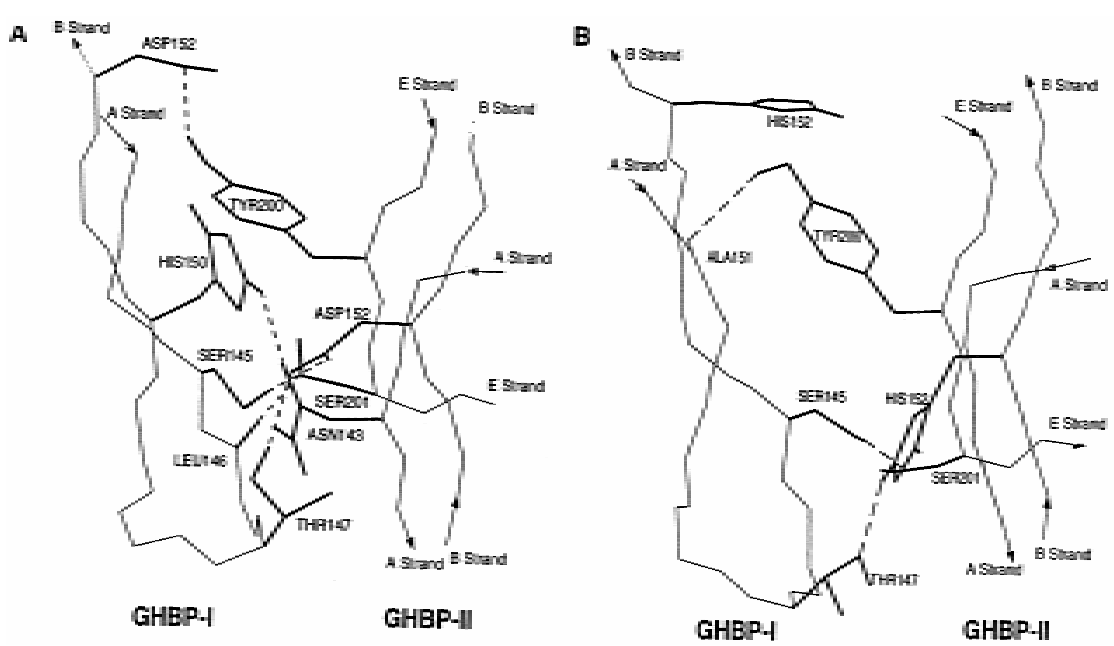

FIGURE 6. Residues involved in the stabilization of the interface between (A) wt and (B) D152H human receptor complexes. Results of 400 ps molecular dynamics are presented. Only residues of interest are shown in bold lines on the first (GHBP-I) and second (GHBP-II) receptor. Dotted lines represent potential hydrogen bonds between receptors. A, B and $\mathrm{E} \beta$-strands of the GHBP involved in the dimerization are shown (thin lines).

axes are displaced $1 \AA$ from those of the wt and are closer than in wt by about $1 \AA$. The most affected regions are those where the $A s p 152$ residues are located, as shown by shaded circles in Fig. 7. To study the effects of these displacements on the interface between receptors, distances between Asp152 on one receptor and the nearest residue on the other were measured; they remain the same in wt and mutant receptors (about $6 \cdot 5 \AA$ ). Indeed the change in relative distance between $\mathrm{C}$-terminal domains of hGHBP induced by the mutation, as measured by the displacement of centers of gravity of slices, is associated to a rotation (Fig. 7) which presumably keeps these two domains at the same distance.
In contrast, in the rat complex both axis displacement and rotation around the axis are absent. Thus the D152H mutation does not affect the mean relative orientation of the extracellular C-terminal domain of each receptor molecule.

\section{DISCUSSION}

The first defect of the GH receptor identified in patients with Laron syndrome and normal binding activity of GH receptor/GHBP was the substitution of aspartate 152 by histidine (Duquesnoy et al. 1994). In these patients, the molecular defect of the $\mathrm{GH}$ receptor results in failure to transduce 

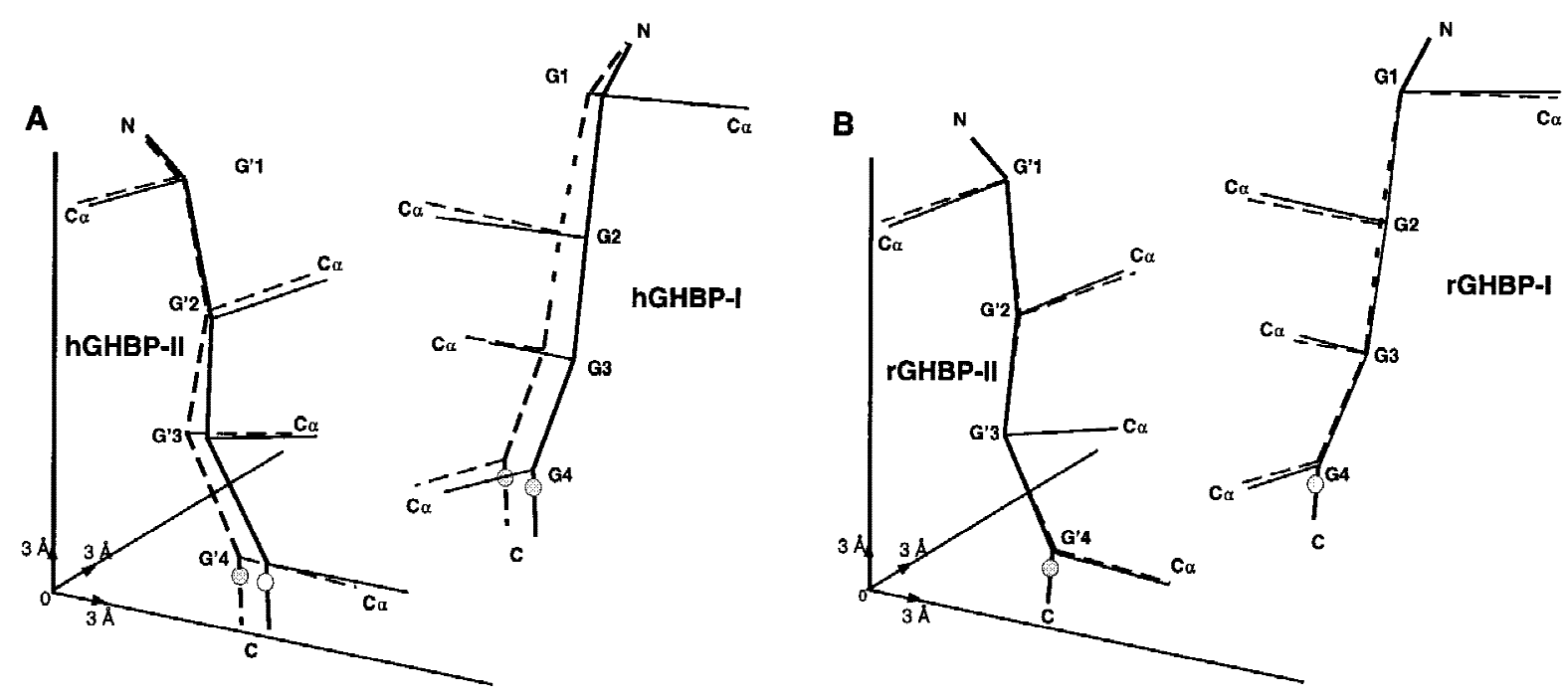

FIGURE 7. Schematic representation of the axis of extracellular C-terminal domains of the GHR involved in (A) human and (B) rat complexes. Results of 400 ps molecular dynamics are presented. Centers of gravity of slices chosen (see Materials and Methods) to visualize the axis of GHBP C-terminal domains are shown: G1, G2, G3, G4 for GHBP-I and G'1, G'2, G'3, G'4 for GHBP-II. Bold lines represent axes of wild-type receptors and dotted lines those of $\mathrm{D} 152 \mathrm{H}$ mutant receptors. $\mathrm{C} \alpha$ points represent $\alpha$ carbons of residues chosen to detect rotations around the axis. Shaded circles represent the position on the axis of $A s p 152$. The D152H mutation makes the two extracellular hGHBP domains closer by $1 \AA$ in the rat receptor, and induces a rotation in the human receptor.

the signal, whereas GH binding affinity is not altered.

$\mathrm{GH}$ binding to its receptor induces dimerization of the receptor, and activation of the tyrosine kinase JAK2 (Argetsinger et al. 1993) which results in phosphorylation of the kinase, of the receptor, and of a cascade of other cellular proteins including members of the Stat (signal transducers and activators of transcription) protein family (Heldin 1995). The development of functional systems has made possible the evaluation of $\mathrm{GH}$ receptor mutants for their ability to transduce hormonal signals (Goujon et al. 1994, Sotiropoulos et al. 1994). Our goal has been to compare the binding characteristics, expression and function of the D152H and of the wild-type GHR.

Specificity and affinity of the human wild-type GHR expressed in 293 cells were those expected for a human receptor (Hocquette et al. 1989). The binding affinity of the $\mathrm{D} 152 \mathrm{H}$ receptor was similar to the wild-type GHR, whereas the number of receptors expressed in 293 cells, whatever the amount of cDNA transfected, was lower for the mutant than for the wild-type GHR. The processing of the mutant receptor to the plasma membrane did not seem to be altered since the number of total receptors was decreased.
A soluble form of mutant human receptors, as well as wild-type receptors, was secreted into the culture medium of transfected cells, suggesting that proteolysis of membrane receptors occurred for both forms. The lower concentration of the mutant GHBP in cell medium was probably related to the lower number of mutant membrane receptors. The GH binding affinity of the wild-type and mutant GHBPs was similar to the affinity reported for human plasma GHBP (Tar et al. 1990). This result was expected, as the binding activity of the plasma GHBP of the patients was found to be normal (Duquesnoy et al. 1994). A decrease in the serum GHBP concentration reflecting a low number of membrane GHRs would be difficult to demonstrate in these patients, considering the wide range of GHBP concentrations found in normal subjects. Moreover, measurement of GH receptor number in accessible cells obtained from the patients is not possible.

Chromatographic profiles of GHBPs generated through proteolysis of mutant and wild-type membrane receptors were similar. We did not observe the presence of two radioactive peaks or a peak eluting at an earlier time, which could have suggested the existence of monomers and dimers of wild-type soluble GHRs, even when high 
concentrations of soluble receptors were incubated with ${ }^{125} \mathrm{I}-\mathrm{hGH}$. Duquesnoy et al. (1994), who identified this mutation in two patients, proposed that the inactivity of the D152H GHR was due to failure to dimerize. Their conclusion was based on chromatographic studies of soluble proteins engineered by introducing a stop codon at position 239 . We also observed that the secreted extracellular domain of the wild-type GHR can bind $\mathrm{GH}$ as a monomer or as a dimer. In contrast, the complex of hGH with secreted mutant extracellular domain appears to consist of receptor monomers only whatever the ratio of soluble receptor versus hormone. Soluble GHRs generated by two different mechanisms must behave differently to explain the discrepancy between the results; dimers of the extracellular domain can probably form more easily in secretory vesicles. Taken together, these results indicate that it is only under particular conditions of secretion that a failure to form dimers can be demonstrated for the mutant GHBP.

Ligand-induced receptor dimerization has been reported for many receptors of the superfamily, and appears to be a critical step for signal transduction (Cunningham et al. 1991, Ishizaka-Ikeda et al. 1993, Heldin 1995). Receptor dimerization has been shown to be necessary for GH effects such as proliferation of promyeloid FDC-P1 cells (Fuh et al. 1992), stimulation of lipogenesis in rat adipocytes and of receptor down regulation in IM-9 lymphocytes (Ilondo et al. 1994). From crosslinking experiments, we obtained evidence that membrane-bound $\mathrm{D} 152 \mathrm{H}$, as well as wild-type GHR, could form dimers, and that similar sized complexes were observed with wild-type and mutant forms of receptors of the different species.

To evaluate the activity of the various forms of the GHR, we studied GH-induced activation of transcriptional activity mediated by Stat5. GH can activate Stat5 phosphorylation and DNA binding to promoter regions of $\mathrm{GH}$-responsive genes, such as the serine protease inhibitor (Spi 2.1) or the $\beta$ casein (Sotiropoulos et al. 1994, Wood et al. 1995). Stat5-mediated transcription was evaluated with multimerized LHRE fused to the luciferase gene; LHRE is present in the promoter of the $\beta$ casein gene. The fact that the mutant human receptor is able to activate Stat5, as shown in the functional test, implies that the mutant receptor is able to dimerize. It has been shown that, at very high concentrations, hGH is able to antagonize signaling by preventing dimerization (Fuh et al. 1992); accordingly, bell-shaped curves were obtained for the dose-responses of $\mathrm{GH}$ in the functional test, suggesting that receptor dimerization occurs with the mutant as well as with the wild-type receptor.
The wild-type and the mutant human GHRs were able to activate Stat5; but, under all conditions of cDNA transfected, the relative luciferase activity remained lower in cells transfected with the D152H GHR cDNA than in cells transfected with the wt GHR cDNA. Low expression is not the only explanation for the impaired activity of the mutant receptor: ten times more cDNA was transfected in 293 cells, so that the GH binding level was higher in cells expressing the mutant GHR; however, under these conditions, maximum luciferase activity, attained at $0 \cdot 1$ to $1 \mu \mathrm{g} / \mathrm{ml} \mathrm{GH}$, remained lower in cells expressing the D152H GHR. The defects of the D152H GHR, including low expression and reduced activity, are more pronounced in cells transfected with small amounts of cDNA, under conditions which are closer to the in vivo situation.

In contrast to the results obtained with the mutant human receptor, D152H rat GHR had normal activity in the functional test. Even if the mutant rat receptor was expressed at a somewhat lower level than the wild-type receptor, it did not alter its functional activity. Thus, despite the fact that the mutation is located in a conserved region of the GHR and involves an invariant residue in the protein of the different species, the consequences of the mutation vary.

These observations can be correlated with results of molecular modeling performed on $\mathrm{GH}-(\mathrm{GHBP})_{2}$ complexes. The D152H mutation affects dimerization by reducing the number of hydrogen bonds between receptors for both human and rat complexes (from 5 to 3 for the human and from 3 to 2 for the rat receptor). It also decreases the interface surface in the case of the human receptor. The fact that the interface surface in wild-type and mutant rat receptors is about half that found in human complexes could be a consequence of the presence in rat receptor of a proline at position 147 instead of a threonine in the human receptor: thus fewer residues are involved in dimerization of the rat receptor.

The substitution of Asp152 by $\mathrm{His}$ at the interface between receptors induces local changes: for instance the role of Asp152 seems to be replaced by Ser201 in the mutant human receptor with respect to hydrogen bond formations, but presumably the mutation does not break the dimerization. In the case of the human receptor, the mutation induces long-distance conformational effects, shown by the displacements of the axis of C-terminal GHBP domains and rotations around these axes, which are not evidenced in the rat complex. However, the calculations were only performed on GHBP, without taking into account the anchorage of receptors into the membrane. 
The calculations are in agreement with our experimental results. The possible formation of dimers with the mutant human GHR is confirmed; however, decreased stability of the homodimer with the mutant receptor is not excluded, and represents a possible explanation for the lower activity of D152H human receptor. Other hypothetical explanations can be proposed: conformational changes induced by the mutation in the human GHR could affect the interaction of the cytoplasmic domains of the two receptors molecules and/or of JAK2 with the receptor.

In conclusion, the substitution of aspartate 152 by histidine is associated with defects in expression and function of the human GHR. Dimeric complexes with the mutant human receptor can form, but may not be equivalent to wild-type GHR dimers. The extreme GH resistance presented by the patients could result from several combined abnormalities, including low receptor expression and partial activity in signal transduction, rather than complete lack of receptor dimerization. Although the aspartate residue at position 152 is conserved in GHR of different species, the mutation in rat GHR does not affect expression and function of the receptor.

\section{ACKNOWLEDGEMENTS}

We are grateful to W Wood (Genentech, San Francisco, USA) for providing the human GHR cDNA and to G Norstedt (Stockholm, Sweden) for the rat GHR cDNA. We wish to thank B De Vos (Genentech) for helpful discussions concerning the molecular structure of the GHR. This work was supported in part by the Institut National de la Santé et de la Recherche Médicale, by RhonePoulenc Rorer and by Roussel-Uclaf. We are grateful to GIS Infobiogen for computer facilities.

\section{REFERENCES}

Argetsinger LS, Campbell GS, Yang X, Witthuhn BA, Silvennoinen O, Ihle JN \& Carter-Su C 1993 Identification of Jak2 as a growth hormone receptor-associated tyrosine kinase. Cell 74 237-244.

Baumann G, Stolar MW, Amburn K, Barsano CP \& DeVries BC 1986 A specific growth hormone-binding protein in human plasma: initial characterization. Fournal of Clinical Endocrinology and Metabolism 62 134-141.

Baumbach WR, Horner DL \& Logan JS 1989 The growth hormone-binding protein in rat serum is an alternatively spliced form of the rat growth hormone receptor. Genes and Development 3 1199-1205.

Bazan JF 1990 Haemopoietic receptors and helical cytokines. Immunology Today 11 350-354.

Berg MA, Argente J, Chernausek S, Gracia R, GuevaraAguirre J, Hopp M, Perez-Juardo L, Rodenbloom A, Toledo
SPA \& Francke U 1993 Diverse growth hormone receptor gene mutations in Laron syndrome. American Fournal of Human Genetics 52 998-1005.

Bernstein FC, Koetzle TF, Williams GJB, Meyer EF, Brice MD, Rodgers JR, Kennard O, Shinamouchi T \& Tasumi M 1977 The protein data bank: a computer based archival file for macromolecular structures. Fournal of Molecular Biology $112535-542$.

Brooks B, Bruccoleri R, Olafson B, States D, Swaminathan S \& Karplus M 1996 CHARMM: a program for macromolecular energy, minimization, and molecular dynamics calculations. Fournal of Computational Chemistry 4 187-217.

Brünger AT, Karplus M \& Petsko GA 1989 Crystallographic refinement by stimulated annealing: application to crambin. Acta Crystallographica A 45 50-61.

Buchanan CR, Maheshwari HG, Norman MR, Morell DJ \& Preece MA 1991 Laron-type dwarfism with apparently normal high affinity serum growth hormone-binding protein. Clinical Endocrinology 35 179-185.

Cunningham BC, Ultsch M, De Vos AM, Mulkerrin MG, Clauser KR \& Wells JA 1991 Dimerization of the extracellular domain of the human growth hormone receptor by a single hormone molecule. Science 254 821-825.

Daughaday WH \& Trivedi B 1987 Absence of serum growth hormone binding protein in patients with growth hormone receptor deficiency (Laron dwarfism). Proceedings of the National Academy of Sciences of the USA 84 4636-4640.

Delehaye-Zervas MC, Mertani H, Martini JF, Nihoul-Fekete C, Morel G \& Postel-Vinay M-C 1994 Growth hormone receptor gene expression in human digestive tissues. Fournal of Clinical Endocrinology and Metabolism 78 1473-1480.

De Vos AM, Ultsch M \& Kossiakoff AA 1991 Human growth hormone and extracellular domain of its receptor: crystal structure of the complex. Science 255 306-312.

Dinerstein H, Lago F, Goujon L, Ferrag F, Esposito N, Finidori J, Kelly PA \& Postel-Vinay M-C 1995 The proline-rich region of the growth hormone receptor is essential for Jak2 phosphorylation, activation of cell proliferation and gene transcription. Molecular Endocrinology 9 1701-1707.

Duquesnoy P, Sobrier ML, Duriez B, Dastot F, Buchanan CR, Savage MO, Preece MA, Craescu CT, Blouquit Y, Goossens M \& Amselem S 1994 A single amino acid substitution in the exoplasmic domain of human growth hormone $(\mathrm{GH})$ receptor confers familial GH resistance (Laron syndrome) with positive $\mathrm{GH}$-binding activity by abolishing receptor homodimerization. EMBO fournal 13 1386-1395.

Fuh G, Cunningham BC, Fukunaga R, Nagata S, Goeddel DV \& Wells JA 1992 Rational design of potent antagonists to the human growth hormone receptor. Science 256 1677-1679.

Goujon L, Allevato G, Simonin G, Paquereau L, Le Cam A, Clark J, Nielsen JH, Djiane J, Postel-Vinay M-C, Edery M \& Kelly PA 1994 Cytoplasmic domains of the growth hormone receptor necessary for signal transduction. Proceedings of the National Academy of Sciences of the USA 91 957-961.

Heldin CH 1995 Dimerization of cell surface receptors in signal transduction. Cell 80 213-223.

Hocquette JF, Postel-Vinay MC, Kayser C, de Hemptinne B \& Amar-Costesec A 1989 The human liver growth hormone receptor. Endocrinology 125 2167-2173.

Ilondo MM, Damholt AB, Cunningham BC, Wells JA, De Meyts P \& Shymko RM 1994 Receptor dimerization determines the effect of growth hormone in primary rat adipocytes and cultured human IM-9 lymphocytes. Endocrinology 134 2397-2403.

Ishizaka-Ikeda E, Fukunaga R, Wood WI, Goeddel DV \& Nagata S 1993 Signal transduction mediated by growth 
hormone receptor and its chimeric molecules with the granulocyte colony-stimulating factor receptor. Proceedings of the National Academy of Sciences of the USA 90 123-127.

Laron Z, Pertzerlan A \& Mannerheimer S 1966 Genetic pituitary dwarfism with high serum concentration of growth hormone - a new inborn error of metabolism? Israel Fournal of Medical Sciences 2 152-155.

Leung DW, Spencer SA, Cachianes G, Hammonds RG, Collins C, Henzel WJ, Barnard R, Waters MJ \& Wood WI 1987 Growth hormone receptor and serum binding protein: purification, cloning, and expression. Nature 330 537-543.

Munson PJ \& Rodbard O 1980 Ligand: a versatile computerized approach for characterization of ligand binding systems. Analytical Biochemistry 107 220-239.

Peeters S \& Friesen HG 1977 A growth hormone binding factor in the serum of pregnant mice. Endocrinology 101 1164-1174.

Peitsch MC 1995 Protein modeling by E-mail. Biotechnology 13 658-660.

Richmond TJ \& Richards FM 1978 Packing of $\alpha$-helices: geometrical constraints and contact areas. Fournal of Molecular Biology 119 537-555.

Savage MO, Blum WF, Ranke MB, Postel-Vinay M-C, Cotterill AM, Hall K, Chatelain PG, Preece MA \& Rosenfeld RG 1993 Clinical features and endocrine status in patients with GH insensitivity (Laron syndrome). Fournal of Clinical Endocrinology and Metabolism 77 1465-1471.

Smith WC, Kuniyoshi J \& Talamantes F 1989 Mouse serum growth hormone $(\mathrm{GH})$ binding protein has $\mathrm{GH}$ receptor extracellular and substituted transmembrane domains. Molecular Endocrinology 3 984-990.
Sotiropoulos A, Goujon L, Simonin G, Kelly PA, Postel-Vinay M-C \& Finidori J 1993 Evidence for generation of the growth hormone-binding protein through proteolysis of the growth hormone membrane receptor. Endocrinology 132 $1863-1865$.

Sotiropoulos A, Perrot-Applanat M, Dinerstein H, Pallier A, Postel-Vinay M-C, Finidori J \& Kelly PA 1994 Distinct cytoplasmic regions of the growth hormone receptor are required for activation of Jak2, mitogen-activated protein kinase, and transcription. Endocrinology 135 1292-1298.

Spencer SA, Hammonds RG, Henzel WJ, Rodriguez H, Waters MJ \& Wood WI 1988 Rabbit liver growth hormone receptor and serum binding protein: purification, characterization and sequence. Fournal of Biological Chemistry 263 7862-7867.

Tar A, Hocquette JF, Souberbielle JC, Clot JP, Brauner R \& Postel-Vinay M-C 1990 Evaluation of the growth hormonebinding proteins in human plasma using HPLC-gel filtration. Fournal of Clinical Endocrinology and Metabolism 71 1202-1207.

Wood TJJ, Sliva D, Lobie PE, Pircher T, Gouilleux F, Wakao H, Gustafsson JA, Groner B, Norstedt G \& Haldosen LA 1995 Mediation of growth hormone-dependent transcriptional activation by mammary gland factor/Stat5. Fournal of Biological Chemistry 270 9448-9453.

Ymer SI \& Herington AC 1985 Evidence for specific binding of growth hormone to a receptor like-protein in rabbit serum. Molecular and Cellular Endocrinology $\mathbf{4 1}$ $153-161$

REVISED MANUSCRIPT RECEIVED 12 January 1998 